\title{
Research of Cross-listed stocks' price correlation in the case of Shanghai-Hong Kong Stock Connect program
}

\author{
Tiansheng $\mathrm{Xu}^{1, \mathrm{a}}$, Xiaokang Wang ${ }^{2, \mathrm{~b}}$, \\ Zongzheng $\mathrm{Xi}^{3, \mathrm{c}}$, Jiong Zhang ${ }^{4, \mathrm{~d}}$, Jing Gao ${ }^{5, \mathrm{e}}$ \\ ${ }^{12345}$ Capital University of Economics and Business, Beijing, China, 100070 \\ axuts@cueb.edu.cn, bxiaokangwang@outlook.com, \\ c1191054117@qq.com, d68
}

071250@163.com, ègaojing@cueb.edu.cn

Keywords: Shanghai-Hong Kong Stock Connect program; Cross listed stocks; Price linkage

\begin{abstract}
With the continuous development of global economic integration and regionalization, since the 1980s, a growing number of emerging economies in the securities market choose to open itself in the international market for finance with cross-listings. Hong Kong as a special administrative region of P.R.C, has an inalienable relationship with mainland in political, cultural and economic fields, including the securities market. The China Securities Regulatory Commission and the Securities \& Futures Commission implemented Shanghai-Hong Kong Stock Connect program in November 17, 2014. There were 68 "A+H" stocks listed in both markets before Shanghai-Hong Kong Stock Connect program. This paper focuses on the cross-listed stocks and the Hang Seng AH (A) and $\mathrm{AH}(\mathrm{H})$ index in the context of the overall level of " $\mathrm{A}+\mathrm{H}$ " shares to study the impact of the implementation of Shanghai-Hong Kong Stock Connect program on the correlation of cross-listed stocks and the mutual guiding relationship between them.
\end{abstract}

\section{Introduction}

Since the twentieth century, the development pattern of globalization and regionalization show an increasing significance in the global economic sector. Capital markets have no exception, more and more enterprises choose to list in different stock markets to achieve larger scale financing with cross-listing. (this article focus on the price correlation of cross-listed stocks between Shanghai and Hong Kong. For the sake of convenience, the term "A + H" stock is used instead of cross-listed stocks in Shanghai and Hong Kong.) As of the end of July 2016, there are a total of 89 stocks listed in both mainland and Hong Kong. In 89 cross-listed sticks, 68 of them were listed in both Shanghai and Hong Kong before Shanghai-Hong Kong Stock Connect program, while 18 of them were listed in both Shenzhen and Hong Kong. Since this article focus on Shanghai-Hong Kong connect program, the scope of discussion narrowed to 68 stocks cross-listed in both Shanghai and Hong Kong.

Shanghai-Hong Kong Stock Connect is a program allowing investors in Hong Kong and Shanghai to buy stocks listed in the other market from local securities companies (or brokers), enable the capital to flow between Shanghai and Hong Kong. China Securities Regulatory Commission and Securities \& Futures Commission of Hong Kong made the announcement on April 10th 2014 that the stock transaction under Shanghai-Hong Kong Stock Connect will be started on November 17 th.

It is valuable to research the linkage in such a conduction. For investors, the linkage of same stock between two markets is important as it will increase profit and decrease risk. For companies want to be listed in both Hong Kong and Shanghai stock exchange, the linkage of stocks can produce reference for IPO price. Also, the research about Shanghai-Hong Kong Stock Connect can provide insight for similar programs. 


\section{Analysis on the Causes of the $\mathrm{A}+\mathrm{H}$ price linkage}

Linkage in stock market refers to effect that the prices of two or more stocks rise and fall at the same time. A linkage can also refer to synchronized or balanced states of index or stock among different stock exchange or stocks. Currently, the idea that there is a linkage existing among stock markets have been recognized by the theoretic research community, but no consensuses have been reached for the cause of this effect. Different reason has been proposed and the most representative one are linkage caused by fundamental and behavior factor.

Fundamental factors cause linkage as proposed by efficient-market hypothesis. This effect has been reinforced in modern economy, for the information asymmetry is reduced between different markets. Behavioral factors cause linkage mainly via two approaches: first, different investment field and style investors hold; second, irrational factors associated with small and medium investors. It is the interaction of the decisions of different investors in the stocks market that leads to the daily changes in the index and the price of the individual stocks. This principle also applies to the linkage between China's market and Hong Kong's market.

\section{Analysis of the Linkage of $\mathrm{A}+\mathrm{H}$ stocks}

This article focuses on the linkage on cross-listed stocks, and selects Hang Seng China AH Index as the object of study to verify the linkage within $\mathrm{A}+\mathrm{H}$ stocks market. As for time range, we selected May 5, 2005 after the change of shareholder structure in which circulated stocks and untradeable stocks were decoupled to November 17th, 2014 when Shanghai-Hong Kong Stock Connect was established and November 17, 2016, after the program has been established for two years. Sixty-eight groups of $\mathrm{A}+\mathrm{H}$ stocks were compared in order to evaluate the linkage before and after the establishing of Shanghai-Hong Kong Stock Connect program.

Pre-progressing was used to ensure statistical data consistency by retaining only the data when both two market were open to counteract the differences between the two places on the arrangement of the holidays. Since the fluctuation during the daytime is significant, we sample the mean of open price, close price, maximum, minimum as the price of any given day, which smooth the fluctuation while keeping cointegration relationship within index sequence, the Granger causality, and the correlation. The logarithmic processing was used to better simulate the trend of the index.

The following table shows the correlation coefficient between $\mathrm{AH}(\mathrm{A})$ and $\mathrm{AH}(\mathrm{H})$ shares from the perspective of correlation and examines the overall situation of price linkage of 68 cross-listed stocks as a whole.

Table 3.1 Correlation coefficient analysis table

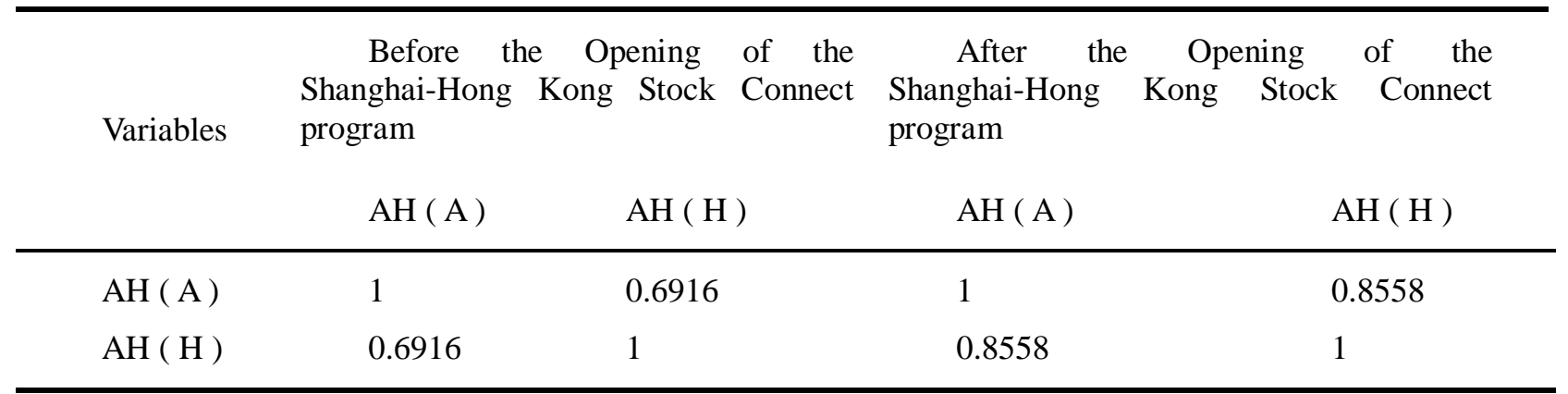

Inferred from the result shown in Table 3.1, the correlation coefficient between two markets were 0.6916 before the opening of the Shanghai-Hong Kong Stock Connect program. And after the opening of that, the correlation coefficient between two markets were 0.8558 , which indicates a higher degree of correlation. The results of the correlation coefficient analysis confirm that the introduction of the Shanghai-Hong Kong Stock Connect program has played a role in advancing the linkage between the cross-listed stock's prices.

It is particularly important to conduct long-term cointegration analysis of the time series of the two sets of indicators, as the main goal of research of this paper is to test the price linkage of cross-listed 
stocks. But the cointegration analysis of the time series must satisfy the time series stability prerequisites, so we have to first perform unit root test on two series of logarithmic variables.

In this paper, ADF tests were chosen to evaluate smoothness. Table 3.2 shows the results of the test:

Table 3.2 Smoothness analysis table

\begin{tabular}{lllllll}
\hline \multirow{2}{*}{ Variables } & ADF & Threshold & & & \multirow{2}{*}{ P Value } & Conclusion \\
& Statistics & $1 \%$ & $5 \%$ & $10 \%$ & \\
\hline $\ln A H$ (A) & -2.360543 & -3.961702 & -3.411599 & -3.121669 & 0.40 & Unstable \\
dlnAH (A) & -26.37765 & -3.961702 & -3.411599 & -3.121669 & 0.00 & Stable \\
$\operatorname{lnAH~(H)~}$ & -2.942424 & -3.691669 & -3.411597 & -3.127668 & 0.15 & Unstable \\
dlnAH (H) & -43.80776 & -3.691669 & -3.411597 & -3.127668 & 0.00 & Stable \\
\hline
\end{tabular}

From the results, we can see that the two logarithmic time series are non-stationary sequence, as $\ln \mathrm{AH}(\mathrm{A})$ has a $\mathrm{P}$ value of $0.40 ; \ln \mathrm{AH}(\mathrm{H})$ has a $\mathrm{P}$ value of 0.15 , although $\ln \mathrm{AH}(\mathrm{H})$ is smoother $\ln \mathrm{AH}$ (A) but they are both above 0.05 threshold, so that both are non-stationary time series. However, it can be observed from differential sequence $\operatorname{dn} \mathrm{AH}(\mathrm{A})$ and $\operatorname{dn} \mathrm{AH}(\mathrm{H})$ both have a $\mathrm{P}$ value of 0 , the first order differential sequence did not include the unit root, so two series are stable after differentiating.

The Johansen cointegration test is the most important method to determine whether the time series variables of each group have the long-term cointegration relationship. Table 3.3 shows the sequence of long-term cointegration test of $\mathrm{A}+\mathrm{H}$ 's $\mathrm{A}$ index and $\mathrm{H}$ index in logarithmic scale.

Table 3.3 Johansen long-term cointegration analysis

\begin{tabular}{llllll}
\hline Duration & $\begin{array}{l}\mathrm{H} \quad 0 \quad \text { (make } \\
\text { assumptions) }\end{array}$ & $\begin{array}{l}\text { Characteristic } \\
\text { root }\end{array}$ & Trace & $\begin{array}{l}5 \% \text { significant } \\
\text { threshold }\end{array}$ & Prob.** \\
\hline $\begin{array}{l}\text { Before Shanghai-Hong Kong } \\
\text { Stock Connect program }\end{array}$ & $\begin{array}{l}\text { None } \\
\text { (cointegration } \\
\text { does not exist) }\end{array}$ & 0.012352 & $\begin{array}{l}32.054 \\
93\end{array}$ & 15.49471 & 0.0001 \\
After Shanghai-Hong Kong & $\begin{array}{l}\text { None } \\
\text { (cointegration } \\
\text { Stock Connect program }\end{array}$ & 0.073764 & $\begin{array}{l}33.507 \\
86\end{array}$ & 15.49471 & 0.0000 \\
\hline
\end{tabular}

According to the result, no matter before or after the establishing of the Shanghai-Hong Kong Stock Connect program, at the given confidence level, the original hypothesis that shows that during this period, two series of indicator have a long-term cointegration relationship as a balanced time series by linear combination can be constructed. On the other hand, when comparing in time segments, $\mathrm{P}$ value for trace was 0.0001 before Shanghai-Hong Kong Stock Connect program and decreased to 0 after opening. The test results above show that after the opening of that program the linkage between two markets were increased.

The causal relationship between the two markets' stocks’ price and the effect of Shanghai-Hong Kong Stock Connect program were also evaluated. The results are shown in Table 3.4.

Table 3.4 Granger causality analysis

\begin{tabular}{llllll}
\hline Sample Duration & Null hypothesis & $\begin{array}{l}\text { Number } \\
\text { samples }\end{array}$ & F statistic & P Value & Conclusion \\
\hline $\begin{array}{l}\text { Before Shanghai-Hong } \\
\text { Kong Stock Connect }\end{array}$ & $\begin{array}{l}\text { AH(A) is not Granger } \\
\text { cause for AH(H) }\end{array}$ & 2106 & 8.96120 & 0.0001 & Deny \\
program & $\begin{array}{l}\text { AH) is not Granger } \\
\text { cause for AH(A) }\end{array}$ & 2106 & 3.99713 & 0.0185 & Deny \\
$\begin{array}{l}\text { After Shanghai-Hong is not Granger } \\
\text { Kong Stock Connect }\end{array}$ & $\begin{array}{l}\text { cause for AH(H) } \\
\text { AH(H) is not Granger } \\
\text { program }\end{array}$ & 495 & 3.75964 & 0.2585 & Accept \\
\hline
\end{tabular}


From the results, it can be seen that $\mathrm{AH}(\mathrm{A})$ is not a Granger cause of $\mathrm{AH}(\mathrm{H})$, as the $\mathrm{P}$ value is less than the threshold 0.05; $\mathrm{AH}(\mathrm{H})$ is not that of $\mathrm{AH}(\mathrm{A})$ for the same reason. The result shows that before the opening of the program $\mathrm{AH}(\mathrm{A})$ index and the $\mathrm{AH}(\mathrm{H})$ index are not bidirectional guided.

After the opening of Shanghai-Hong Kong Stock Connect program, AH (A) is not Granger cause for $\mathrm{AH}(\mathrm{H})$ is accepted, while $\mathrm{AH}(\mathrm{H})$ is not Granger cause for $\mathrm{AH}(\mathrm{A})$ were denied. The results show that, after the opening of the program the change in $\mathrm{AH}(\mathrm{A})$ indicator doesn't guide the change in $\mathrm{AH}(\mathrm{H})$ while $\mathrm{AH}(\mathrm{H})$ guide $\mathrm{AH}(\mathrm{A})$. It can be inferred that after the opening Shanghai-Hong Kong Stock Connect program, stock's performance in Hong Kong leads A+H stocks in both Hong Kong and China mainland. The implementation of Shanghai-Hong Kong Stock Connect program has led to the inflow of a large amount of mainland funds into the capital market in Hong Kong, which has a far greater impact on Hong's market as it is relatively smaller.

\section{Conclusion}

First, since the opening of Shanghai-Hong Kong Stock Connect program, the linkage between $\mathrm{A}+\mathrm{H}$ stocks were enhanced. The correlation coefficient between the two markets increased from 0.6916 to 0.8558 , which shows a significant linkage after the opening of Shanghai-Hong Kong Stock Connect program. The P value for long-term cointegration decreased from 0.004 to 0 as Shanghai-Hong Kong Stock Connect program was established, which shows a better long-term cointegration relationship.

Second, before Shanghai-Hong Kong Stock Connect program, A takes the lead, while after the establishment, $\mathrm{H}$ takes the lead. The Granger model is used to test the causality of $\mathrm{A}$ and $\mathrm{H}$ shares. Before the opening of Shanghai-Hong Kong Stock Connect Program A stock guides the change in $\mathrm{H}$ stocks, after the opening, $\mathrm{H}$ stocks get a substantial increase in influence over A stocks.

\section{Acknowledgement}

This work was supported by Beijing Philosophy and Social Science Project (15ZHB011).

\section{References}

[1] Chen Menggen , Mao Xiaoyuan. An Empirical Study on the Linkage Effect of Price in China 's Stock Market [J]. Finance and Trade Economy 2007 (5): 93-99 + 129

[2] Wang Zhibo, the emergence and development of effective market hypothesis [J]. Journal of South China Normal University ( Social Science Edition ) 2007 (2): 37-43 + 157

[3] Luo Weiwei, Su Yinghong. A Study on the Linkage Effect between A and H Shares before and after QFII - Based on the Data of Dual Listed Companies [J]. Logistics Engineering and Management 2014 (11): 168-170 + 157 